\title{
DIFFERENTIAL BIOFEEDBACK INTERVENTION IN MODERATING INHIBITED PERFORMANCE IN SOCCER
}

\author{
$\underline{\text { Saha, Soumendra }}{ }^{1}$, Saha Srilekha ${ }^{2}$, Nurfarah Ezzaty Binti Mohd Zahir ${ }^{3}$, Debashis $C^{4}$ and \\ Prabal $\mathrm{K} \mathrm{C}^{5}$ \\ 1, $2 \& 3$ School of Health Sciences, \\ Universiti Sains Malaysia, 16150 Kubang Kerian, Kelantan, Malaysia \\ ${ }^{4}$ Bangladesh Cricket Board, \\ Mirpur Sher-e Bangla National Cricket Stadium, Mirpur, Dhaka, Bangladesh \\ ${ }^{5}$ Dept. of Experimental Psychology, \\ Calcutta University, Calcutta, India \\ email: drsoumen@usm.my
}

\begin{abstract}
Performance excellence in soccer crucially depends on mental toughness or more specifically the aspect of emotional flexibility and hardiness of the player. Since indices of projective evaluations can reveal hidden emotional crises and internal conflicts, psychobiological evaluations could substantiate with the inner emotionality revealed to provide etiological information related to performance hindrances in soccer. Present study was carried out to identify the efficacy of skin conductance (Sc) biofeedback in regulation of sudomotor nerve activity (SNA) and of electromyography (EMG) biofeedback in regulation of peak torque and maximal voluntary contraction (MVC) in modification of performance catastrophe in soccer. All of them were assessed with autonomic measures (SNA and Sc amplitude); electromyography evaluation of emotionality and MVC revealed through EMG. Forty National-selection group soccer players of Malaysia were randomly categorized into four groups (Gr. A, $\mathrm{N}=10$, no-intervention control group); Gr. B (who received Sc biofeedback training); Gr. C (received EMG biofeedback intervention) and Gr. D (players who received combined training of Sc and EMG biofeedback intervention). Players of intervention groups received their respective trainings for 12 weeks (15 min.s /day for 3 days/ week). Postintervention analyses revealed marked improvement in the soccer players who received Sc and EMG biofeedback intervention, and the combined biofeedback training was evident as most efficient intervention technique in modulating emotionality as well as muscle potentiality. Analysis of variance and repeated measure of ANOVA were done to observe shared aetiology in the form of direct, inverse and supportive relationships between psychobiological and emotional indices related to performance crises in soccer. Comprehensive understanding of the confounding relationships between subjective feelings emotionality and corroborative psychobiological indices as predictor of high performance was achieved.
\end{abstract}

Keywords: Biofeedback, Skin conductance, EMG, Soccer 


\section{INTRODUCTION}

Success in soccer performance could be viewed as optimal extent of facilitative combination of multiple aspects ranging from skillful adoption of basic skills, tactical preparations, physiological conditioning and psychological and psychobiological adaptations. A player's ability to regulate his or her own psychological conditions mostly rely on cognitive-emotional competence (Saha et al. 2013a; Wegner \& Pennebaker, 1993), which involves the deliberate use of strategies to change or maintain thoughts, feelings, or actions (Totterdell \& Leach, 2001).

Since our previous researches have already confirmed about the facilitative influence of psychobiological and cognitive components as well as emotional regulation as key features predicting performance excellence in soccer (Saha et al. 2013a \& c), focus of researches should have been concentrating on issues beyond cognitive-emotional and psychobiological competence. Here we wanted to pay attention to the issues of neuromuscular ability and electrical muscle potentiality, which would be able highlight on other significant dimensions pertaining to the issues like fatigability, muscle potentiality and maximal voluntary contraction as determinants of peak performance in soccer.

The methodological concerns would be more important aspect, in detecting surface electromyographic (sEMG) signals, which are susceptible to contain the signals originating in the muscle, which are accompanied by various prevalent and unavoidable noise components. These noise components vulnerably contaminate the surface EMG signal and may lead to an erroneous interpretation of the signal (Luca et al. 2010). Strikingly enough these errors especially occur and contaminate the findings, when the signals are obtained during dynamic contractions. Thus the data which would be considered as the most important and valid information pertaining to electrical muscle potentiality responses and which are supposed to provide authentic information concerning the physiology and anatomy of muscles, are supposed to be wasted.

With such a background and in search of a valid methodology to obtain further information related to science of optimal soccer performance, the present study was carried out -

1) To know about the differential efficacy of biofeedback interventions on cognitiveemotional regulation in the soccer players;

2) To compare the efficacy of skin conductance and electromyography biofeedback intervention in regulation of emotional changes in the players;

3) To compare the efficacy of the two different biofeedback intervention techniques in regulation of maximal voluntary contraction and fatigability in the players;

4) To justify the influence of combined introduction of skin conductance and electromyography biofeedback training in regulation of emotionality as well as muscle potentiality. 


\section{METHODOLOGY}

\subsection{Participants}

Altogether forty highly skilled and consistently high performing Malaysian male soccer players aging between 19.9 and 22.1 years (mean age $=20.8$ and $\mathrm{SD}=1.13$ ) were selected by the respective selectors, volunteered as the participants in this study. They were mostly state selection-level athletes and they were selected unanimously by three expert coaches, while they were preparing for their forthcoming soccer season (2014). The sample size was calculated using $\mathrm{G}$ power 3.0.17 (Faul et al. 2007). The power of the study was set at $80 \%$ with $95 \%$ confidence interval and the effect size $\mathrm{f}$ was set at 0.25 . They were randomly categorized into four groups (Gr. A, $\mathrm{N}=10$, no-intervention control group); Gr. B (who received Sc biofeedback training); Gr. C (received EMG biofeedback intervention) and Gr. D (players who received combined training of Sc and EMG biofeedback intervention).

\subsection{Materials Used}

1. Skin Conductance Apparatus (ProComp5 Infintiy, USA 2013) was used to assess the extent of autonomic regulation as index of emotionality in the participants.

2. Electromyography Recording Apparatus (MegaTrac ME6000, USA 2008) - was administered to evaluate the muscle potentiality; maximal voluntary control and fatigability of the participants.

\subsection{Procedure}

In this present study all of the participants were at first evaluated on the psychobiological analyses and EMG activity analyses for the pre-intervention analyses. For the psychobiological analyses (viz., autonomic regulation and orienting amplitude were assessed employing measures of skin conductance activities- Sc), and electromyography analyses (viz., maximal voluntary contraction or MVC and fatigability or Fatigue AEMG) were done on all the participants. Special cares were taken to nullify any erroneous influence from any subject-relevant; sequence-relevant and stimulus-relevant interference, which could have significant manipulative effect on the psychological make-up of the participants. All of these assessments were done following standard procedures (methodology detailed in the Saha et al 2005; 2012 \& 2013a \& b).

Participants were subjected to psychobiological evaluation of emotionality (employing the ProComp5 Infinity apparatus) following standard method of administration (methodology detailed in Saha et al. 2012 \& 2013b). Phasic or habituation paradigm Sc activity indices were decomposed as - basal phasic Sc; SF or NS-SCR (non-specific Sc response, which is also termed as spontaneous fluctuation or SF) and stimulus-specific orienting response measures (viz. amplitude) (Saha et al. 2012; 2013b \& 2013d). For the EMG evaluation MegaTrac ME 6000 Apparatus was used, and the Raw EMG data were rectified and integrated by RMS (root-mean-square), and thereafter Band Pass filtration of the data, the Waveform data were assessed to derive Maximal voluntary contraction (MVC) and Fatigue score (FatigueAEMG). 
Thereafter players were randomly categorized into four groups (Gr. A, $\mathrm{N}=10$, nointervention control group); Gr. B (who received Sc biofeedback training); Gr. C (received EMG biofeedback intervention) and Gr. D (players who received combined training of Sc and EMG biofeedback intervention). Players of intervention groups received their respective trainings for 12 weeks (15 min.s /day for 3 days/ week). Mid-term analyses on all of the afore-mentioned variables were done after the $6^{\text {th }}$ week and finally the post-intervention analyses were done at the end of the $12^{\text {th }}$ week following similar protocols.

The data were treated with SPSS 20.0 and reports on correlation analyses, prompted the authors to look into prediction analyses. Thereafter analyses of two-way repeated measure of ANOVA were performed to justify the relative contribution of psychobiological variables in predicting apprehensiveness in the high performing players.

\section{RESULTS}

Reports on descriptive statistics were summarized in the Tables 1, which represented somewhat consistency in the data obtained from the participants of the four groups (hereafter Gr. A, B, C \& D). Data revealed that there existed mostly moderate and in some cases lower extents of standard deviation indices, which clarified that the data were considerably free from huge dispersions. Moderate dispersions are considered as somewhat generalised features of psychobiological and electrophysiological analyses outcomes.

Table 1 - Descriptive measure and significance of variance amongst the four groups

\begin{tabular}{|c|c|c|c|c|c|c|c|c|c|c|c|c|c|c|c|}
\hline \multirow{3}{*}{$\stackrel{气}{\bar{\Xi}}$} & \multicolumn{3}{|c|}{$\begin{array}{c}\text { Phasic Skin } \\
\text { Conductance } \\
\text { (Log micro mhos) } \\
\text { Obtained on three } \\
\text { different phases of exp. }\end{array}$} & \multicolumn{3}{|c|}{$\begin{array}{l}\text { Orienting Amplitude } \\
\text { (Log microsiemens) } \\
\text { Obtained on three } \\
\text { different phases of exp. }\end{array}$} & \multicolumn{3}{|c|}{$\begin{array}{l}\text { Spontaneous Fluctuation } \\
\text { (Sudomotor nerve } \\
\text { activity- SNA) (No.s) } \\
\text { Obtained on three } \\
\text { different phases of exp. }\end{array}$} & \multicolumn{3}{|c|}{$\begin{array}{l}\text { EMG Maximal Voluntary } \\
\text { Contraction (MVC)( } \mu \mathrm{Vs}) \\
\text { Obtained on three } \\
\text { different phases of exp. }\end{array}$} & \multicolumn{3}{|c|}{$\begin{array}{l}\text { Fatigue AEMG ( } \mu \mathrm{Vs}) \\
\text { Obtained on three } \\
\text { different phases of exp. }\end{array}$} \\
\hline & $\begin{array}{l}\text { I } \\
\end{array}$ & III & 2 III & I & $\overline{\text { II }}$ & III & $\begin{array}{l}\text { I } \\
\end{array}$ & $\begin{array}{c}\text { II } \\
\end{array}$ & 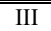 & I & II & III & I & II & III \\
\hline & $\begin{array}{c}\mathrm{M} \\
\mathrm{SD}\end{array}$ & $\begin{array}{l}\mathrm{M} \\
\mathrm{SD}\end{array}$ & $\begin{array}{c}\mathrm{M} \\
\mathrm{SD}\end{array}$ & $\begin{array}{c}\mathrm{M} \\
\mathrm{SD}\end{array}$ & $\begin{array}{l}\mathrm{M} \\
\mathrm{SD}\end{array}$ & $\begin{array}{c}\mathrm{M} \\
\mathrm{SD}\end{array}$ & $\begin{array}{l}\mathrm{M} \\
\mathrm{SD}\end{array}$ & $\begin{array}{c}\mathrm{M} \\
\mathrm{SD}\end{array}$ & $\begin{array}{c}\mathrm{M} \\
\mathrm{SD}\end{array}$ & $\begin{array}{c}\mathrm{M} \\
\mathrm{SD}\end{array}$ & $\begin{array}{c}\mathrm{M} \\
\mathrm{SD}\end{array}$ & $\begin{array}{c}\mathrm{M} \\
\mathrm{SD}\end{array}$ & $\begin{array}{c}\mathrm{M} \\
\mathrm{SD}\end{array}$ & $\begin{array}{c}\mathrm{M} \\
\mathrm{SD}\end{array}$ & $\begin{array}{l}\mathrm{M} \\
\mathrm{SD}\end{array}$ \\
\hline Gr. A & $\begin{array}{l}4.85 \\
2.07\end{array}$ & $\begin{array}{l}5.71 \\
2.84\end{array}$ & $\begin{array}{l}4.94 \\
1.47\end{array}$ & $\begin{array}{l}.42 \\
.11\end{array}$ & $\begin{array}{l}.39 \\
.16\end{array}$ & $\begin{array}{l}.44 \\
.09\end{array}$ & $\begin{array}{c}4 \\
2.83\end{array}$ & $\begin{array}{c}6 \\
1.51\end{array}$ & $\begin{array}{l}8 \\
.95\end{array}$ & $\begin{array}{l}385.4 \\
132.8\end{array}$ & $\begin{array}{l}415.9 \\
251.8\end{array}$ & $\begin{array}{l}401.8 \\
253.5\end{array}$ & $\begin{array}{c}412.6 \\
39.5\end{array}$ & $\begin{array}{c}-365.4 \\
42.7\end{array}$ & $\begin{array}{c}-354.8 \\
84.9\end{array}$ \\
\hline Gr. B & $\begin{array}{l}5.28 \\
1.36\end{array}$ & $\begin{array}{l}6.87 \\
2.03\end{array}$ & $\begin{array}{l}7.12 \\
1.34\end{array}$ & $\begin{array}{l}.50 \\
.08\end{array}$ & $\begin{array}{l}.54 \\
.15\end{array}$ & $\begin{array}{l}.62 \\
.11\end{array}$ & $\begin{array}{c}6 \\
2.17\end{array}$ & $\begin{array}{c}4 \\
2.11\end{array}$ & $\begin{array}{c}3 \\
1.24\end{array}$ & $\begin{array}{l}374.9 \\
128.6\end{array}$ & $\begin{array}{l}601.8 \\
214.9\end{array}$ & $\begin{array}{l}651.8 \\
125.7\end{array}$ & $\begin{array}{c}719.1 \\
56.4\end{array}$ & $\begin{array}{c}714.4 \\
45.8\end{array}$ & $\begin{array}{c}481.7 \\
95.1\end{array}$ \\
\hline Gr. C & $\begin{array}{l}4.97 \\
2.21\end{array}$ & $\begin{array}{l}5.79 \\
2.11\end{array}$ & $\begin{array}{l}6.47 \\
2.54\end{array}$ & $\begin{array}{l}.48 \\
.12 \\
\end{array}$ & $\begin{array}{l}.57 \\
.13\end{array}$ & $\begin{array}{l}.59 \\
.12\end{array}$ & $\begin{array}{c}5 \\
1.89 \\
\end{array}$ & $\begin{array}{c}4 \\
1.05\end{array}$ & $\begin{array}{c}4 \\
.81\end{array}$ & $\begin{array}{l}401.7 \\
141.9\end{array}$ & $\begin{array}{l}731.1 \\
182.8\end{array}$ & $\begin{array}{l}745.8 \\
157.2\end{array}$ & $\begin{array}{c}684.4 \\
61.5 \\
\end{array}$ & $\begin{array}{c}445.8 \\
58.9\end{array}$ & $\begin{array}{c}371.8 \\
24.8\end{array}$ \\
\hline Gr. D & $\begin{array}{l}5.03 \\
2.05\end{array}$ & $\begin{array}{l}7.28 \\
1.88 \\
\end{array}$ & $\begin{array}{l}8.37 \\
2.06 \\
\end{array}$ & $\begin{array}{l}.46 \\
.15 \\
\end{array}$ & $\begin{array}{l}.61 \\
.18\end{array}$ & $\begin{array}{l}.65 \\
.17 \\
\end{array}$ & $\begin{array}{c}3 \\
1.48 \\
\end{array}$ & $\begin{array}{c}5 \\
1.47\end{array}$ & $\begin{array}{l}4 \\
.79 \\
\end{array}$ & $\begin{array}{l}353.1 \\
109.5\end{array}$ & $\begin{array}{l}647.6 \\
152.4\end{array}$ & $\begin{array}{l}801.6 \\
203.4 \\
\end{array}$ & $\begin{array}{c}496.3 \\
76.4 \\
\end{array}$ & $\begin{array}{c}433.7 \\
43.8 \\
\end{array}$ & $\begin{array}{c}501.7 \\
24.8\end{array}$ \\
\hline $\begin{array}{l}\text { KW- } \\
\text { values }\end{array}$ & ثે & $\stackrel{\infty}{i}$ & م. & 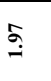 & 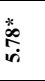 & (ל) & ले & $\stackrel{*}{7}$ & 赵 & $\stackrel{\infty}{\oplus}$ & 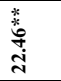 & 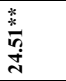 & 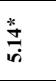 & \begin{tabular}{l}
$\frac{k}{*}$ \\
\multirow{2}{*}{} \\
2 \\
2
\end{tabular} & 草 \\
\hline
\end{tabular}

Table 1 however also represented differences observed amongst the participants of the groups A, B, C \& D on all of the variables assessed, which implied that pre-existing differences were present between the soccer players, who were categorised into different groups, on one of the psychobiological (i.e., phasic Sc) and one EMG (i.e., fatigability) variable. Further to that, mid-term analyses and post-intervention analyses revealed that participants of different groups had significant difference in between them, implying that those observed differences could be attributed to the differential interventions received by the participants.

Table 2 - Mauchly's Test of Sphericity ${ }^{a}$

Measure: MEASURE_1 Obtained from the Soccer Players 


\begin{tabular}{|c|c|c|c|c|c|c|c|}
\hline \multirow[t]{2}{*}{ Within Subjects Effect } & \multirow{2}{*}{$\begin{array}{c}\text { Mauchly's } \\
\text { W }\end{array}$} & \multirow{2}{*}{$\begin{array}{c}\text { Approx. Chi- } \\
\text { Square }\end{array}$} & \multirow[t]{2}{*}{ df } & \multirow[t]{2}{*}{ Sig. } & \multicolumn{3}{|c|}{ "Epsilon ${ }^{\mathrm{a}}$} \\
\hline & & & & & $\begin{array}{l}\text { Greenhouse- } \\
\text { Geisser }\end{array}$ & $\begin{array}{l}\text { Huynh- } \\
\text { Feldt }\end{array}$ & $\begin{array}{l}\text { Lower- } \\
\text { bound }\end{array}$ \\
\hline Sc-SF & .018 & 208.919 & 2 & 000 & .505 & .505 & .500 \\
\hline Amplitude & .022 & 197.874 & 2 & ב.000 & ב.506 & ".506 & (.500 \\
\hline EMG MVC & .000 & 770.643 & 9 & 2.000 & .252 & .252 & .250 \\
\hline Fatigue AEMG & .019 & 397.471 & 2 & .000 & .617 & .617 & .500 \\
\hline \multicolumn{8}{|c|}{ Tests the null hypothesis that the error covariance matrix of the orthonormalized transformed dependent variables is proportional to an identity matrix. } \\
\hline \multicolumn{8}{|c|}{$\begin{array}{l}\text { a. Design: Intercept } \\
\text { Within Subjects Design: Sc - SF + Amplitude + EMG MVC + Fatigue AEMG }\end{array}$} \\
\hline
\end{tabular}

Reports from the Table 2 revealed the results of Mauchly's test of sphericity for each of the main effects of the psychobiological and EMG parameters. Tests indicated that all of the main effects violated the assumption of sphericity and therefore the F-values for those effects were required to be corrected. Thus all of the outputs (results of ANOVA with corrected $F$ values), are represented in the Table 3 (Table of tests of within-subjects effects), which are reported in the next section one by one.

Table 3 - Tests of Within-Subjects Effects

Measure: MEASURE_1 Obtained from the Soccer Players

\begin{tabular}{|l||c||c||c||c||c||c||}
\hline \hline Source & $\begin{array}{c}\text { Type III Sum } \\
\text { of Squares }\end{array}$ & df & Mean Square & F & Sig. \\
\hline \hline Sc SF & Greenhouse-Geisser & 2405197.21 & 1.01 & 2383556.89 & 320.97 & .000 \\
\hline \hline Amplitude & Greenhouse-Geisser & 2177169.82 & 1.01 & 2152944.81 & 292.07 & .000 \\
\hline \hline EMG MVC & Greenhouse-Geisser & 4173276.48 & 1.02 & 4137767.77 & 291.93 & .000 \\
\hline \hline Fatigue AEMG & Greenhouse-Geisser & 4609716.21 & 1.02 & 3228356.36 & 308.48 & .000 \\
\hline
\end{tabular}

We can report the results as for the soccer performers, 'there was a significant main effect of Sc SF, $F(1.01,53.48)=320.97, p<.000$, which implied that, if effects of other variables are ignored, autonomic conditions of the Skin conductance SF were different from each other (table 3). Similarly the output for amplitude could be reported as $F(1.01,53.6)=292.07, p<$ .000 , which were different from each other. For the output of EMG MVC could be reported as $F(1.02,53.46)=291.93, p<.000$, which were different from each other. Similarly the output for Fatigue EMG could be reported as $F(1.01,53.6)=308.48, p<.000$, which were different from each other.

\section{DISCUSSION}

Outcomes of the between the groups variance (Table 1) revealed that, in cases of phasic Skin conductance analyses and fatigability revealed through AEMG (Fatigue AEMG) pre-existing differences were evident. Although in the electrophysiology and psychobiology researches these types of variances could arise, all of the data were filtered and rectified based on RMS corrections. More so, apart from the afore-mentioned variables, in case of other variables preexisting differences were not observed, and hence observed changes in mid-term as well as in the post-intervention analyses could be attributed to the Sc biofeedback; EMG biofeedback and combined intervention (Sc \& EMG biofeedback) trainings followed for 12 weeks. Here 
in-depth analyses of the obtained descriptive analyses however revealed that introduction of differential intervention techniques also had definite and evidential impacts onto the changes in the phasic Sc and fatigability parameters, and hence post-intervention modifications in phasic Sc component and fatigability were observed.

Observed mean difference (Table 1) further revealed that, soccer players who received differential biofeedback interventions, had relatively better psychobiological i.e., autonomic competence, and which is evident in their larger autonomic response amplitude; lesser NSSCR or SF responses and higher phasic Sc scores and higher electrical muscle potentiality (characterised by higher extent of maximal voluntary contraction and lesser extent of fatigability), compared to their control condition counterparts.

In the Tables 2 and 3 reports of repeated measure of ANOVA done considering within and between interactions revealed that the main effects of the psychobiological and EMG parameters violated the assumption of sphericity and therefore the $F$-values for those effects were required to be corrected. Table 3 reports featured tests of within-subjects effects, which revealed that the participants of all of the intervention groups could significantly gain from the interventions to which they were introduced.

At this point we intended to pay more attention to the outcomes based on inter-group differences, (Table 1), and Kruskal-Wallis analysis reports and the observed mean differences however revealed that, the combined intervention group of participants could benefit mostly from the Sc as well as EMG biofeedback training since they were observed to have best phasic Sc conditioning; highest extent of orienting amplitude and highest levels of MVC in EMG compared to their counterparts (control participants as well as participants who received either Sc biofeedback or EMG biofeedback intervention only). Out of the two other intervention groups, the players who received EMG biofeedback training, were observed to benefit mostly from the intervention in terms of improvements in the electrophysiological measures of fatigability and in maximal voluntary contraction scores.

Here if we pay attention to the implications of the observed findings, we can postulate that observed high extent of emotional flexibility in the players who received Sc biofeedback training was contributed by higher extents of spontaneous fluctuation (SFs). While combined introduction of Sc as well as EMG biofeedback contributed in improvements in autonomic as well as peripheral neural activations, which might have prompted the participants to cope with the muscular potential deficiencies as well as autonomic adaptations too. Here we observed differential contributory influences of the interventions on the soccer players, since soccer players are more engaged in faster reaction performances (Togari \& Takahashi, 1977, Suzuki et al. 1988, Saha et. al. 2013a); they are supposed to require higher-order maximal voluntary control of their quadriceps muscles. Our previous researches however also pointed out that the soccer players of South-East Asian origins were mostly observed as having delayed autonomic recovery, which perhaps had been a source of complication to some of the players (Saha et. al., 2005; 2013c). Further to that, observed moderate extent of SFs in the soccer players appeared to have been markedly controversial (Bach et. al., 2010), since 
previous researches from identical experimental set-ups revealed SFs serve as indices of startle response characterised by higher extents of sudomotor nerve firing (Bach et.al. 2010; Dawson et. al. 2000; Saha et. al., 2005; 2012a; 2013a \& b) resulting in high-strung emotionality. Similarly observed considerably larger amplitude in the players who received Sc biofeedback intervention only, and also those who received combined intervention of EMG as well as Sc biofeedback interventions, compared to their counterparts, could be considered as characteristic index of orienting response, which is also index of optimal emotional adaptation (Saha et. al. 2012; 2013c \& d).

\section{CONCLUSIONS}

- $\quad$ Skin Conductance biofeedback was observed to modulate emotional startle response better than the other intervention technique used.

- $\quad$ EMG biofeedback technique was observed as a better intervention technique in regulation of muscle fatigability and maximal voluntary contraction in the soccer players.

- Combined introduction of skin conductance as well as EMG biofeedback training have been observed to obtain maximal benefits in both regulation of emotional turmoil as well as in the control of electrical muscle potentiality.

\section{ACKNOWLEDGEMENT}

Dr. Soumendra Saha was supported by the Short-Term Research Grant of the Universiti Sains Malaysia (Account no. 304/PPSK/61312065). Authors of the present study are indebted to the Grant Authorities for having awarded to carry out the study.

\section{REFERENCES}

Bach DR, Friston KJ, Dolan RJ. Analytic measures for quantification of arousal from spontaneous skin conductance fluctuations. International Journal of Psychophysiology. 76, 52-55 (2010).

Dawson, M. E., Schell, A. M., \& Filion, D. L. (2000). The Electrodermal System. New York, Cambridge University Press.

Faul, F., Erdfelder, E., Lang, A.- G., \& Buchner, A. (2007). G*Power 3: A flexible statistical power analysis program for the social, behavioral, and biomedical sciences. Behavior Research Methods, 39, 175-191.

Luca C J D, Gilmore L.D, Kuznetsov M, Roy S H. (2010). Filtering the surface EMG signal: Movement artefact and baseline noise contamination. Journal of Biomechanics, 43, 1573-1579.

Saha, Srilekha; Biswas, D.; Chattopadhyay, P. K., and Saha, S. (1998). Family size and emotional adjustment in children. Social Science International, 14: 1\&2, 35-40.

Saha S., Mukhopadhyay Pritha, Chattopadhyay P. K., Biswas D., \& Saha Srilekha. (2005). Arousal modulation as predictor of achievement motivation in high soccer 
performers. Reading in Sports Psychology. Jitendra Mohon and Meena Sehgal (Eds.) Friends Publications, India, 116-146.

Saha S.: Saha Srilekha and Asyraf, B. R. (2013c). Corroborative psychobiological indices explaining young adolescent emotionality. Procedia Social and Behavioral Sciences., 91, $614-623$.

Saha, Srilekha; Saha, S and Chattopadhyay, P. K. (2013b). Effect of muscle relaxation training as a function of improvement in attentiveness in children, Procedia Social and Behavioral Sciences. 91, 606 -613.

Saha, S., Saha Srilekha; Chowdhury, D.; Fahim N. A \& Salah Uddin M. (2012). In search of predictors for reaction ability related to high performance in Cricket. Social Science International, 28 (1), $1-18$.

Saha Srilekha, Saha, S., Krasilschikov O., Ismail, M. S. (2013d). Cognitive-emotional predictors of anticipation and reaction ability as mediator for performance excellence in south-asian athletes, Procedia Social and Behavioral Sciences, 91, 624 -631.

S, Soumendra; S, Srilekha; Mazlan, M. A. B. M. and Arriffin, M. I. B. M (2013a). Effect of emotional regulation on performance of soccer skills, Procedia Social and Behavioral Sciences. 91, $594-605$.

Suzuki, S., et. al. (1988). Analysis of the goalkeeper's diving motion, in Science and Football (eds T. Reilly. A. Lees, K. Davids and W. J. Murphy), E. \& F. N. Spon, London, 468475.

Togari, H. \& Takahashi, K. (1977). Study of 'whole-body reaction' in soccer players. Proceeding of the Department of Physical Education (College of General Education, University of Tokyo), 11, 35-41.

Totterdell, P. \& Leach, D. (2001). Negative mood regulation expectancies and sports performance: an investigation involving professional cricketers. P. Totterdell *, D. Leach, 2, 249-265.

Wegner, D. M., \& Pennebaker, J. W. (1993). Changing our minds: An introduction to mental control. In D. M. Wegner, \& J. W. Pennebaker (Eds.), Handbook of mental control, 112, Englewood Cliffs, NJ: Prentice Hall. 